\title{
RELIABILITY OF RADIOLOGICAL MEASUREMENTS IN THE ASSESSMENT OF THE CHILD'S HIP
}

\author{
N. S. BROUGHTON, D. I. BROUGHAM, W. G. COLE, M. B. MENElauS
}

From the Royal Children's Hospital, Melbourne

\begin{abstract}
We investigated the reproducibility of the various radiological methods of assessment of hip dysplasia by making 474 assessments of hips and quantifying the inter-observer and intra-observer variation. There was a wide range of variability between the readings made by different observers and by one observer on two occasions. A measurement of acetabular index has to be given a range of $\pm 6^{\circ}$ in order to be $95 \%$ confident of including the true measurement.

We found the most helpful measurements to be the acetabular index, up to the age of eight years; the centre-edge angle, over the age of five years; and Smith's c/b ratio and neck-shaft angle. We feel, however, that the change in value over a series of radiographs in the same child is much more valuable. Single readings of all the radiological measurements investigated in this study were unreliable.
\end{abstract}

The pelvic radiograph is an important part of the assessment of the child with a dysplastic hip. Various measurements have been advocated to help in this assessment and large studies have been reported, which aimed to define normal ranges at different ages for the acetabular index (Tönnis 1976), the head-teardrop distance (Eyring, Bjornson and Peterson 1965) and the centre-edge (CE) angle (Fredensborg 1976). Previous studies have been based on single observations by one observer.

Few studies have assessed the accuracy of these and other radiological measurements made of the child's dysplastic hip. Prior to undertaking a large scale study of hip dysplasia, we have attempted to quantify the variation of these measurements.

\section{PATIENTS AND METHODS}

We assessed 474 hip radiographs of children aged between four months and 15 years. Of these, 179 were before and after treatment for congenital dislocation of the hip $(\mathrm{CDH}), 79$ were the contralateral hip to one

N. S. Broughton, FRCS, Clinical Research Fellow D. I. Brougham, FRACS, Clinical Research Fellow W. G. Cole, MSc, PhD, FRACS, Deputy Director

M. B. Menelaus, MD, FRCS, FRACS, Director

The Department of Orthopaedics, Royal Children's Hospital, Flemington Road, Parkville, Victoria 3052, Australia.

Correspondence should be sent to Mr M. B. Menelaus. (C) 1989 British Editorial Society of Bone and Joint Surgery $0301-620 \mathrm{X} / 89 / 1184 \$ 2.00$

J Bone Joint Surg [Br] 1989;71-B:6-8. with $\mathrm{CDH}$, and 216 were apparently normal joints, seen on radiographs taken during micturating cystourethrography.

The acetabular index, Smith's $\mathrm{c} / \mathrm{b}$ and $\mathrm{h} / \mathrm{b}$ ratios (Smith et al. 1968), the amount of femoral head uncovering (Dickens and Menelaus 1978), the headteardrop distance and the neck-shaft angle were measured in all the radiographs (Figs 1 and 2). The ACM angle, the $\mathrm{M}-\mathrm{Z}$ distance and the centre-edge angle were measured in 170 hips of children over five years of age (Figs 3 and 4). These measurements were made by two of the authors (NSB and DIB) as a preliminary to a large scale study of hip dysplasia. The observers agreed on the precise definition of the landmarks to be used and a perspex sheet was placed over the radiographs so that

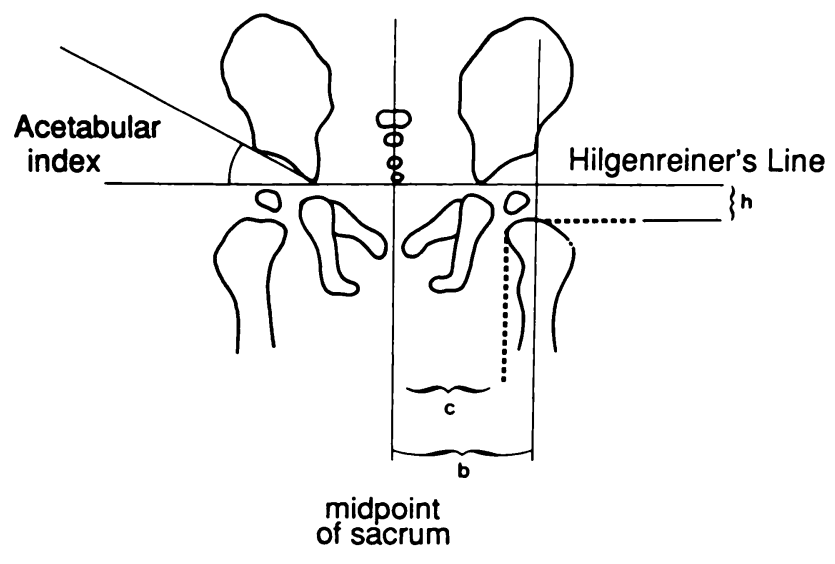

Fig. 1

Diagram to show the distances used to calculate Smith's $c / b$ and $h / b$ ratios. 


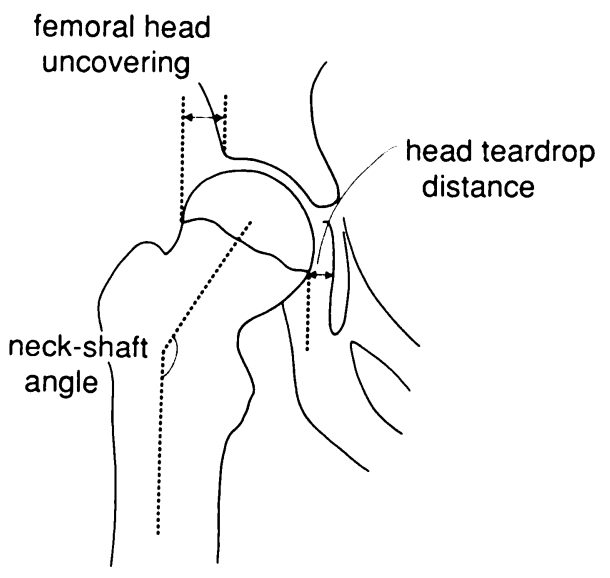

Fig. 2

Three radiological measurements.

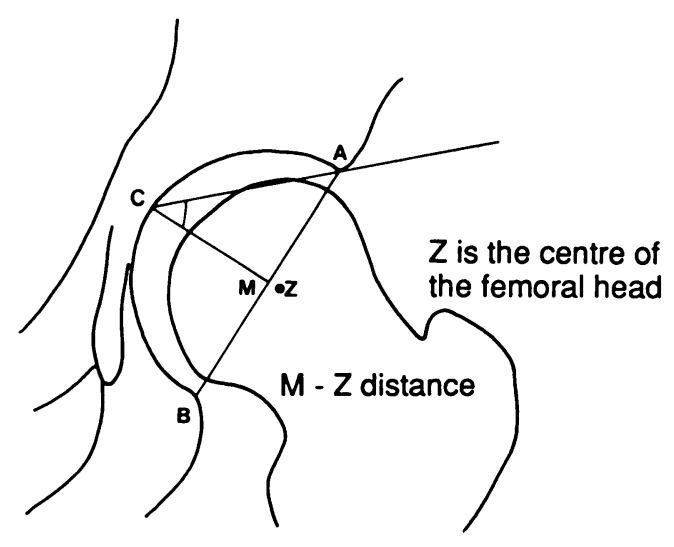

Fig. 3

Radiological measurements. $M$ is the mid-point of $A B$, and gives the $M-Z$ distance. $M C$ is perpendicular to the line $\mathrm{AMB}$ and gives the $\mathrm{ACM}$ angle.

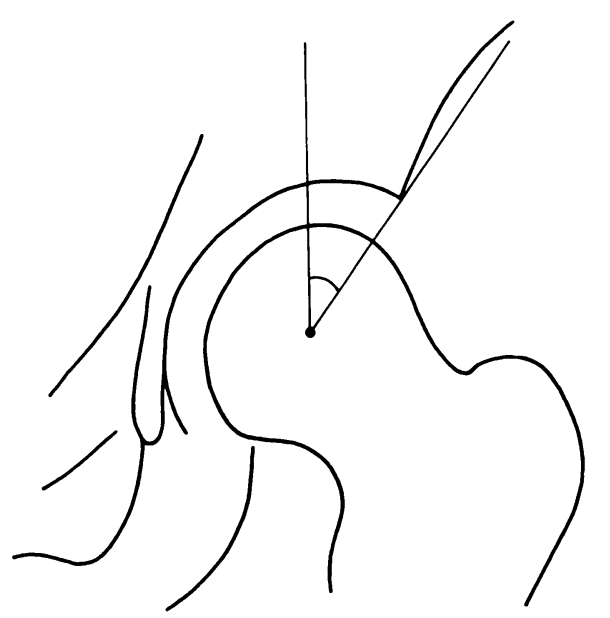

Fig. 4

The centre-edge angle is that between a perpendicular to Hilgenreiner's line and a line from the centre of the femoral head to the edge of the acetabulum. lines could be drawn without influencing subsequent measurements on the same film.

The study was in three parts. First, 126 hips were assessed by the same observer on two occasions, separated by at least two weeks. Secondly, 100 hips were assessed independently by two observers, and finally 60 hips were assessed by the same observer on two radiographs taken on the same day.

\section{RESULTS}

Intra-observer variation. The difference between two readings by the same observer for each measurement was calculated. The range of differences for the acetabular index was -10 to $+9^{\circ}$. The $95 \%$ prediction interval was $\pm 6^{\circ}$ which means that if, for example, the acetabular index is read as $25^{\circ}$, then the $95 \%$ confidence range is 19 to $31^{\circ}$ (Ingelfinger et al. 1983). Table I shows the range of readings for each measurement and the $95 \%$ prediction interval for the next reading. In 28 cases the lateral wall of the teardrop was so poorly defined that the observer was unable to measure the head-teardrop distance.

Other variations. Very similar variations were found both between observers and between measurements on two radiographs taken on the same day (Table I).

Analysis of variation. Further analysis showed that the variability in readings did not depend on the magnitude or degree of abnormality of the readings; there was similar variation in both normal and abnormal values. The conclusion from the statistics in Table I is that the range of differences for measurements by the same observer, between observers and between two radio-

Table I. Measurements undertaken and variation between observations

\begin{tabular}{|c|c|c|c|}
\hline & \multirow{2}{*}{$\begin{array}{l}\text { Range of } \\
\text { observations }\end{array}$} & \multicolumn{2}{|c|}{$\begin{array}{l}\text { Differences - } \\
\text { 95\% prediction intervals }\end{array}$} \\
\hline & & Intra-observer & Inter-observer \\
\hline $\begin{array}{l}\text { Acetabular index } \\
\text { (degrees) }\end{array}$ & 4 to 47 & \pm 6.1 & \pm 5.5 \\
\hline $\begin{array}{l}\text { Centre-edge angle } \\
\text { (degrees) }\end{array}$ & 0 to 42 & \pm 9.3 & \pm 9.1 \\
\hline $\begin{array}{l}\text { Head-teardrop distance } \\
(\mathrm{mm})\end{array}$ & 5 to 21 & \pm 2.8 & \pm 2.7 \\
\hline $\begin{array}{l}\text { Femoral uncovering } \\
\text { (degrees) }\end{array}$ & -3 to 16 & \pm 3.5 & \pm 3.8 \\
\hline $\begin{array}{l}\text { ACM angle } \\
\text { (degrees) }\end{array}$ & 40 to 58 & \pm 4.7 & \pm 4.5 \\
\hline $\begin{array}{l}\mathbf{M}-\mathbf{Z} \text { distance } \\
(\mathrm{mm})\end{array}$ & 0 to 17 & \pm 3.3 & \pm 3.1 \\
\hline $\begin{array}{l}\text { Neck-shaft angle } \\
\text { (degrees) }\end{array}$ & 121 to 188 & \pm 10.4 & \pm 12.6 \\
\hline Smith's c/b ratio & 0.57 to 1.05 & \pm 0.04 & \pm 0.06 \\
\hline Smith's $h / b$ ratio & 0.00 to 0.22 & \pm 0.05 & \pm 0.05 \\
\hline
\end{tabular}


graphs were similar. Smith's $\mathrm{c} / \mathrm{b}$ ratio was the most reliable of the measurements, giving the smallest $95 \%$ prediction interval.

\section{DISCUSSION}

Little work has been published to quantify inter-observer differences in radiological measurements of a dysplastic hip. Precision in such measurements cannot be assumed; the Catterall grouping of Perthes' disease has been shown to be subject to inter-observer error (Hardcastle et al. 1980). Our study shows that in the measurements of the child's pelvic radiograph there can be a wide difference in the values recorded by different observers and by one observer on two occasions.

Variability may occur because of difficulty in defining the landmarks used in making these measurements. The lateral margin of the acetabulum in the dysplastic hip is often rounded rather than coming to a sharp, well-demarcated point. Hilgenreiner's line, which is drawn across the lowest point of the ilium, is difficult to define when the triradiate cartilage ossifies. For this reason we do not advocate the use of the acetabular index in children aged over eight years.

The centre of the femoral head is difficult to define in the young child because the ossific nucleus is eccentric in many cases. Therefore we feel that the centre-edge angle and $\mathrm{M}-\mathrm{Z}$ distance cannot be measured accurately in a child under five. We found the definition of the inferior acetabular angle to be difficult in both child and adolescent, so we do not advocate the use of ACM angle or $\mathbf{M}-\mathbf{Z}$ distance.

In both the normal and the dysplastic hip the lateral margin of the teardrop is often poorly defined so that the head-teardrop distance could not be measured. We advocate the use of Smith's $c / b$ ratio as a more reliable measurement of lateral displacement of the femoral head.

The measurements made of the child's radiograph are useful in order to differentiate the normal from the obviously dysplastic hip but, in doubtful cases, the figures may be inaccurate. Progression of a value over a series of radiographs in the same child is much more valuable than a single measurement (Harris, LloydRoberts and Gallien 1975), and in our series we often found that a verbal description of acetabular development or femoral displacement was as valuable as any single measurement.
Acetabular index and centre-edge angle are widely used and normal ranges have been defined in other studies (Fredensborg 1976; Tönnis 1976). Although variation occurs we will continue to use them in the assessment of the dysplastic hip. However in view of the wide variation, we are keen not to burden the orthopaedic surgeon with other radiological measurements of this area.

In our future studies we will be recording the acetabular index up to eight years of age, the centre-edge angle over five years, and Smith's c/b ratio and the neckshaft angle at all ages. We shall rely more on a description of the hip and the progression of that appearance over a series of radiographs rather than on single measurements. Single readings of all the measurements made in this study of the child's radiographs, are unreliable.

N. S. Broughton and D. I. Brougham undertook this work whilst employed by the Royal Children's Hospital Research Foundation, and $N$. S. Broughton was awarded financial aid from the Wellcome Research Foundation and the Ethicon Foundation. We are grateful for the help of Dr Simon Sheather, Lecturer in Statistics, University of Melbourne in the interpretation of our data.

Although none of the authors have received or will receive benefits for personal or professional use from a commercial party related directly or indirectly to the subject of this article, benefits have been or will be received but are directed solely to a research fund, foundation, educational institution, or other non-profit institution with which one or more of the authors is associated.

\section{REFERENCES}

Dickens DRV, Menelaus MB. The assessment of prognosis in Perthes disease. J Bone Joint Surg [Br] 1978;60-B:189-94.

Eyring EJ, Bjornson DR, Peterson CA. Early diagnostic and prognostic signs in Legg-Calvé-Perthes disease. Am J Roentgenol $1965 ; 93: 382-7$.

Fredensborg N. The CE angle of normal hips. Acta Orthop Scand 1976;47:403-5.

Hardcastle PH, Ross R, Hamalainen M, Mata A. Catterall grouping of Perthes' disease: an assessment of observer error and prognosis using the Catterall classification. J Bone Joint Surg [Br] $1980 ; 62-B: 428-31$.

Harris NH, Lloyd-Roberts GC, Gallien R. Acetabular development in congenital dislocation of the hip: with special reference to the indications for acetabuloplasty and pelvic or femoral realignment osteotomy. J Bone Joint Surg [Br] 1975;57-B:46-52.

Ingelfinger JA, Mosteller F, Thibodeau LA, Ware JH. Biostatistics in clinical medicine. New York, etc: Macmillan Publishing Co, Inc, 1983.

Smith WS, Badgley CE, Orwig JB, Harper JM. Correlation of postreduction roentgenograms and thirty-one-year follow-up in congenital dislocation of the hip. J Bone Joint Surg [Am] $1968 ; 50-A: 1081-98$.

Tönnis D. Normal values of the hip joint for the evaluation of $x$-rays in children and adults. Clin Orthop 1976;119:39-47. 